\section{FEMINISMO E POLÍTICA NA MÚSICA ERUDITA NO BRASIL}

RevistaMúsica | vol. 19, n.2 | pp. 220-240 | jul. 2019

\section{Thais Fernandes Santos}

thaisfrs@yahoo.com.br|UFRGS

\section{FEMINISM AND POLITICS IN BRAZILIAN CLASSICAL MUSIC}

Recebido em: 18/05/2019

Aprovado em: 15/06/2019

\section{RESUMO}

Este estudo busca discutir a representação das mulheres em posições de destaque na música erudita brasileira. Para tanto, verificamos e contabilizamos o número de mulheres regentes, solistas e compositoras convidadas pela Orquestra Sinfônica do Estado de São Paulo (OSESP), durante as duas fases da orquestra: antes e durante a gestão de Marin Alsop, única mulher a assumir o cargo de regente titular e diretora artística da instituição. Acreditamos que trabalhos quantitativos sobre o papel das mulheres em áreas específicas podem contribuir para a discussão sobre a reprodução da hierarquia do conhecimento e a

representatividade feminina. Os resultados apresentados no estudo são significativos e apontam para a diferença de gênero em relação às funções de prestígio, expressando, assim, a estrutura dos saberes e a inserção das mulheres no campo político das instituições. A discussão apresentada nesta pesquisa exploratória aponta para a necessidade de aprofundamento na temática do feminismo e da política, buscando avançar o conhecimento na área.

\section{PALAVRAS-CHAVE:}

Feminismo; música erudita; política; orquestras brasileiras.

\section{ABSTRACT}

The present paper aims to discuss the representation of women in highlights positions in Brazilian classical music verifying the number of invited people as a conductor, soloist, and composer by São Paulo Symphony Orchestra. We analyzed two specific moments of the symphonic group: before and during the management by Marin Alsop. She became the principal conductor and music director of the

OSESP in 2012-2019, furthermore, she is the only woman to assume this position. We believe that quantitative studies may contribute to the

investigation of the invisibility of women in classical music. Also, we discuss the reproduction of the rooted knowledge structure. Our findings are relevant and point to the

difference in gender and the relationship between highlight position and knowledge structure. Therefore, we expect that this exploratory investigation contributes to other research involving the feminism and politic in classical music in Brazil.

KEYWORDS:

Feminism; Classical music; Politics; Brazilian orchestras. 


\section{FEMINISMO E POLÍTICA NA MÚSICA ERUDITA NO BRASIL}

Thais Fernandes Santos

thaisfrs@yahoo.com.br | UFRGS

\section{Introdução}

O presente artigo discute algumas questões e resultados relativos à temática feminismo e política na música erudita, a partir da contabilização de mulheres e homens convidados a participar como músicos de destaque na Orquestra Sinfônica do Estado de São Paulo (OSESP), durante duas distintas fases da orquestra: antes e durante a gestão de Marin Alsop, única mulher a assumir o cargo de regente titular e diretora artística da instituição. Marin Alsop é nova-iorquina e foi a primeira mulher a ser premiada com o Koussevitzky Conducting Prize, do Tanglewood Music Center, onde foi aluna de Leonard Bernstein.

A pesquisa abrange compositores, performers e maestros da "música ocidental de concerto" ou "música erudita", entendendo que, em sua maioria, eles são sujeitos brancos, acadêmicos e de classe média1 (PETRILLI SEGNINI, 2014; ROSA et al, 2013). Embora esse seja nosso atual recorte de análise, ressaltamos a importância da expansão de um estudo interseccional, envolvendo discussões não somente sobre gênero, mas também acerca da raça e classe.

Salientamos, ainda, que este trabalho é um estudo exploratório, ainda em fase inicial, de uma pesquisa quantitativa que busca problematizar conceitos e noções importantes para a compreensão das dinâmicas sociais em torno da questão de gênero, com enfoque para a desigualdade de oportunidades no meio musical, a ausência ou invisibilidade da presença feminina em posições de destaque e as formas de poder e dominação da figura masculina.

Compreendendo a abrangência da temática, reconhecemos a nossa longa trajetória de pesquisa. Entretanto, apontaremos para dados relevantes a serem discutidos e esperamos contribuir para uma discussão crítica acerca da visibilidade feminina e das relações de gênero e poder no cenário da música erudita e na produção do conhecimento na área de feminismo e música no Brasil.

\footnotetext{
${ }^{1}$ Em trabalho publicado em 2014, a pesquisadora Liliana Segnini aponta que a área da música é um espaço constituído, em sua maioria, de homens brancos e que os performers que assumem posições de solistas são, além disso, pertencentes a uma elite econômica e social. Sendo assim, a pesquisadora ressalta a importância da categoria de análise relacionada às classes sociais, de gênero e raça a partir da compreensão do campo de trabalho artístico.
} 
Buscamos, assim, referenciar e reconhecer, ao longo do texto, um mapeamento da produção de conhecimento sobre a visibilidade de mulheres em trabalhos relacionados com gênero e música, feminismo e política e produção de conhecimento na área de música no Brasil.

\subsection{0 feminino e a política}

Atualmente, a discussão envolvendo o feminismo e a política torna-se relevante ao identificarmos as teorias feministas, as quais se debruçam sobre os direitos das mulheres, colocando em debate a sustentação das hierarquias sociais e do funcionamento das instituições públicas e privadas. No livro Feminismo e Política Uma introdução (MIGUEL; BIROLI, 2014), os autores explicam que o campo político é historicamente compreendido como um ambiente masculino, exercendo influência significativa nas vidas das pessoas, podendo seus efeitos, por isso, atuarem negativamente sob as mulheres ${ }^{2}$ e outros integrantes de grupos sociais subalternizados.

As atuações negativas são impostas por meio de obstáculos para tais grupos alcançarem posições de destaque e influência, mesmo depois de ocuparem cargos por meio de voto popular. A divisão dos papéis convencionais entre feminino e masculino corrobora para que o patriarcado e as políticas públicas - que muitas vezes são poucas e fracas - sejam ainda mais punitivas com as mulheres, principalmente as que são mães e trabalhadoras.

Dessa forma, buscamos entender as relações de gênero enraizadas nas organizações de forma desigual, condizentes com o status quo. A cientista política Flávia Biroli (2018) aponta os obstáculos enfrentados pelas mulheres a partir das dinâmicas sociais de hierarquias da divisão do trabalho e discute os elementos materiais e simbólicos que

se estrelaçam à seletividade própria aos espaços formais de representação, historicamente masculinos. Algumas análises têm-se concentrado na socialização de gênero e nas condições para que a "ambição política" se manifeste. Elas remetem à reprodução de papéis, competências e julgamentos no cotidiano familiar, escolar e nos meios de comunicação e, com diferentes ênfases, à conformação masculina e sexista das campanhas e do ambiente político. (BIROLI, 2018, p.171)

Assim, a divisão de trabalho no ambiente público e privado demonstra desvantagens sociais entre os gêneros e indica a representação do espaço público como

\footnotetext{
2 Embora reconheçamos a pluralidade da palavra "mulheres", assim como seus diferentes contextos, tais como "mulheres das classes trabalhadoras", "mulheres negras", "mulheres indígenas" etc, decidimos utilizála, ainda que compreendamos sua categoria não homogênea e não universal. A decisão se justifica pelo fato de ela corresponder a um significado definido e presente na nossa cultura.
} 
masculina. Ainda segundo Biroli (2018), embora as mulheres tenham, em média, mais tempo de educação formal que os homens, há, ainda, uma significativa diferença entre a renda média desses grupos, além de o fato de que a profissionalização não garantiu às mulheres um acesso igualitário nas diferentes posições de trabalho.

É importante notar que essa discussão engloba o recorte estudado neste artigo musicistas da música erudita brasileira -, o que demonstra que estamos nos focando em sujeitos, em sua maioria, de classe média e branca. Por isso, compreendemos a importância de referenciar outros olhares sobre musicistas do Brasil, sendo elas compositoras, intérpretes e maestrinas.

\subsection{O feminino e a música}

A psicóloga Luciana Costa (2016) discute a visão apontada por Amâncio (1992) de que

os diferentes papéis atribuídos a homens e mulheres na sociedade são internalizados através da socialização. Dessa maneira, os gêneros masculino e feminino são constituídos através de conteúdos caracterizadores e de orientações normativas de comportamento que estabelecem e legitimam as suas diferentes posições na sociedade. Essas diferenças são resultados históricos e de construção social, na qual fazem parte o estado, a economia, as ciências, a sexualidade e a família (COSTA, 2016, p. 47).

Ao se debruçar sobre a temática da identidade social de mulheres MC's, como compositoras de rap inseridas no hip hop, a estudiosa explica que as compositoras brasileiras, na história da música popular brasileira, muitas vezes se perderam no plural masculino, já que inseridas no grupo dos “cantores ou compositores do período".

Como consequência, a figura feminina no campo da composição foi fortemente marcada pelo apagamento. As mulheres aparecem, eventualmente, "por suas interpretações e sempre em relação ao universo masculino que as rodeava e as restringia" (COSTA, 2016, p. 49). A autora ainda aponta para a separação das performances das mulheres no universo da música erudita, nas áreas da interpretação e composição musical, indicando o aumento do reconhecimento das intérpretes (comparando a música "popular" e "erudita”). Porém, vale notar, há uma total invisibilidade no campo da composição.

As estudiosas Vanda Freire e Angela Portela (2013) demonstram que a presença das musicistas nem sempre foi relevante para a literatura, muito provavelmente por se tratar de um conhecimento majoritariamente escrito por homens. 
A participação feminina na vida social fora do lar foi muito restrita no período colonial brasileiro. Sob a égide do patriarcalismo, característica marcante desse período a mulher viveu uma situação de subserviência, na qual lhe eram cerceados direitos de escolha e de opinião, entre outros. (FREIRE; PORTELA, 2013, p. 282)

Quando discutimos o espaço público e as instituições políticas como ambientes masculinos, estamos apontando para um espaço político de poder que universaliza determinado grupo e marginaliza outro. Contudo, é importante mencionar a reflexão dos autores Laila Rosa et al (2013) sobre a importância da "pluralidade epistemológica" e referenciarmos outros olhares, principalmente relativo à dicotomia entre público e privado e à visão do feminino como o "sexo frágil", como aponta Sueli Carneiro (1994).

Segundo a pesquisadora, essas generalizações desconsideram as experiências e os conhecimentos das mulheres não brancas, por exemplo, já que as mulheres negras nunca foram consideradas frágeis, sendo escravas durante um longo período da história brasileira, estando completamente ausentes do discurso feminista de que "as mulheres deveriam ganhar as ruas e trabalhar" (CARNEIRO, 1994, p. 190).

Djamila Ribeiro (2017) aponta para o lugar de quem fala e discute o quanto essa posição exerce poder e possibilidade de existência a um indivíduo. Assim, a discussão a respeito da invisibilidade das mulheres em diversas áreas do saber aponta para um debate contemporâneo, envolvendo o conhecimento, a partir de privilégios sociais e, consequentemente, de quem ocupa o lugar de fala. A reflexão é fundamental para perceber que os sujeitos que reivindicam o direito de ter voz estão, na verdade, reivindicando o direito à própria existência. Segundo a filósofa, "a história tem nos mostrado que a invisibilidade mata, o que Foucault chama de 'deixar viver ou deixar morrer"” (RIBEIRO, 2017, p. 43).

No artigo A emergência do campo de música e gênero no Brasil: reflexões iniciais, as autoras Camila Zerbinatti, Isabel Nogueira e Joana Maria Pedro (2018) refletem, a partir de análises de Bell Hooks, importante feminista norte-americana, acerca do ensino nas universidades e qual a consequência da inclusão ou ocultamento de determinados sujeitos. Com isso, deixam clara a necessidade de fala e de escuta de cada uma das vozes que atuam em um determinado campo, além da importância da estimulação de sua expressão, reconhecendo os seus privilégios que vêm do seu lugar de fala.

Luís Felipe Miguel (2014c) aponta para um discurso recorrente na mídia de que a questão feminista foi resolvida, uma vez que as mulheres obtiveram educação, direitos políticos, igualdade no casamento, além de extensiva presença no mercado de trabalho. Entretanto, a significativa dominação masculina ainda é muito presente por meio de estratégias que atuam para produzir mais desvantagens para as mulheres. $\mathrm{O}$ autor 
explica que "formas mais complexas de dominação exigem ferramentas mais sofisticadas para entendê-las" (MIGUEL, 2014c, p. 18).

\subsection{Posições de destaque na música: Compositoras, intérpretes e maestrinas}

A música erudita ocidental é historicamente entendida como um espaço masculino, com a invisibilidade ou, muitas vezes, ausência da presença feminina sendo naturalizada no meio. Ao nos questionarmos sobre nomes femininos da área no meio acadêmico, percebemos a sua pouca representatividade. Contudo, o número de produções científicas envolvendo a temática de gênero e música no Brasil entre os anos de 2000 e 2010, vem aumentando, como indica Zerbinatti et al (2018). As autoras mostram que a maioria das pesquisas envolve compositoras, mas também engloba as diversas práticas musicais de mulheres em "diferentes contextos, papéis e perspectivas teóricas" (ZERBINATTI ET AL, 2018, p. 6).

Segundo as pesquisadoras, observar o hibridismo das práticas e dos processos, além do estudo da inclusão e do reconhecimento dos diferentes lugares de fala, possibilita a compreensão de uma história coletiva que engloba variadas versões, permitindo que diversos sujeitos sejam ouvidos e reconhecidos.

Catarina Domenici (2013) explica sobre a formação dos papéis de compositor e performer e a conexão com a discussão de gênero. A autora mostra que, diante da ameaça de que o conhecimento (comunicação de um saber através da escrita musical) e o corpo (meio no qual a mente humana se expressa no espaço, através do tempo e do som) representam para a autoridade patriarcal,

os homens eram encorajados a desenvolver uma relação teórica com a música, compreendendo seus aspectos científicos e estéticos através da contemplação silenciosa. A prática musical era reservada às mulheres, sendo esperado que aprendessem a tocar um instrumento (DOMENICI, 2013, p. 93)

Destaca, ainda, que a divisão de gênero e a consequente separação entre a teoria e a performance musical refletiram na criação das disciplinas de composição e prática instrumental, fazendo com que, até os dias atuais, os cursos de composição sigam tendências de afastamento da prática musical, enquanto a performance permanece no formato de aulas individuais, se distanciando da teoria e prática composicional.

As autoras Laila Rosa e Isabel Nogueira (2015), em pesquisa realizada para a discussão do tema, apontam para a insivibilização de compositoras mulheres no meio educacional, o que leva à pouca representatividade da figura feminina. Em trabalho anterior, Santos (2018) buscou contabilizar o número de mulheres compositoras que 
tiveram suas obras performadas por orquestras brasileiras (um recorte das orquestras da região sudeste do Brasil), com o intuito de classificar tal invisibilidade, entendendo que essa posição é caracterizada pelo lugar de fala e conhecimento no meio.

Contudo, no presente trabalho, ampliamos a discussão, abrangendo a relação entre o feminismo e a política em uma instituição musical. Dessa maneira, apontamos para a figura feminina nas posições de prestígio, além de propor uma discussão sobre as mulheres em cargos políticos de poder na música.

Analisando a produção científica atual sobre gênero e música no Brasil, percebemos diferentes pontos de diálogo envolvendo diversas vozes, perspectivas e lugares, em um constante esforço de produção epistemológica feminina, tendo as mulheres como agentes do conhecimento e performance musical, atuando como participantes ativas dos saberes e fazeres musicais (ZERBINATTI; NOGUEIRA; PEDRO, 2018).

Biroli (2018) explica que a pouca presença das mulheres em posições de primeiro escalão não significa que elas não atuem nos cargos descritos, mas que sua atuação é dificultada. Quando essa presença existe, por exemplo como Marin Alsop, ela se dá em um ambiente historicamente masculino, como a instituição orquestra sinfônica. Assim, compreendemos que falar de mulheres no meio musical erudito não é apontar para uma ausência - muito pelo contrário, existem mulheres ocupando posições de regente, compositoras e solistas em uma orquestra. Entretanto, tal presença ainda é invisível, uma vez que o espaço masculino corrobora para esse ocultamento.

A invisibilidade das mulheres em posições de destaque ocasiona, nas próximas gerações, uma negação de suas próprias capacidades intelectuais, já que as futuras regentes, solistas e compositoras não identificam uma possibilidade de atingir, profissionalmente uma posição de prestígio como solistas ou maestrinas, por exemplo.

Em sua pesquisa, Petrilli Segnini (2018, p. 242) entrevista musicistas que "expressam limites invisíveis que impedem as mulheres, nas mesmas condições de seus colegas, de ocuparem postos de prestígio em orquestras". Embora relatem que a utilização de biombos ${ }^{3}$ nas audições para a seleção das vagas contribui para a melhora na exclusão, a pesquisadora mostra que há diferença entre o número de homens que assumem a função de chefe de naipe, sendo que, em 2016, na OSESP, 80\% dos chefes de naipe eram homens. Essa informação se torna relevante devido às significativas diferenças salariais entre a posição de chefe de naipe e instrumentistas ou tutti.

3 Os biombos funcionam para a ocultação da identidade do candidato à vaga. 
Assim, entendemos que a corporificação do sujeito feminino em posições de prestígio proporciona um empoderamento na nova geração de mulheres musicistas. A autora Joice Berth aponta para o conceito de empoderamento como um

instrumento de emancipação política e social e não se propõe a 'viciar' ou criar relações paternalistas, assistencialistas ou de dependência entre indivíduos, tampouco traçar regras homogêneas de como cada um pode contribuir e atuar para as lutas dentro dos grupos minoritários (BERTH, 2018, p. 14).

O objetivo deste estudo é, então, investigar o número de mulheres em posições de destaque que fazem parte da trajetória da Orquestra Sinfônica do Estado de São Paulo (OSESP), entre 2000 e 2019, considerando que, durante esse período, temos um importante marco, qual seja, a atuação de Marin Alsop4 (2012-2019) como regente titular e diretora artística da orquestra.

O fato de termos uma mulher como figura principal durante oito anos de uma das maiores orquestra do país nos leva a questões envolvendo o feminismo e a política, tendo a identidade feminina corporificada em uma personagem de poder de uma instituição artística. Para tanto, verificaremos e contabilizaremos o número de mulheres regentes, solistas e compositoras convidadas, durante as duas fases da orquestra: antes e durante a gestão de Marin Alsop.

\section{Metodologia}

\footnotetext{
4 Formada pela Universidade de Yale, é Diretora Musical da Sinfônica de Baltimore desde 2007. Lidera atividades educacionais que atingem mais de 60 mil alunos - em 2008, lançou o OrchKids, programa destinado a prover educação musical, instrumentos e orientação aos jovens menos favorecidos da cidade. Como regente convidada, apresenta-se regularmente com a Filarmônica de Nova York, a Orquestra de Filadélfia, a Sinfônica de Londres e a Filarmônica de Los Angeles, dentre outras. Em 2003, foi a primeira artista a receber, no mesmo ano, o Conductor's Award, da Royal Philharmonic Society, e o título de Artista do Ano, da revista Gramophone. Em 2005, foi a primeira regente a receber a prestigiosa bolsa da Fundação MacArthur e, em 2013, a primeira a reger a "Last Night of The Proms" do festival londrino promovido pela BBC, oportunidade que se repetiu em 2015. Ao lado da Osesp, esteve no mesmo festival em 2012 e 2016. Foi escolhida pela rede CNN como uma das sete mulheres de maior destaque no mundo, no ano de 2013, e, em setembro de 2014, tornou-se membro honorário da Royal Philharmonic Society. Em 2015, assumiu a direção do programa de pós-graduação em regência no Instituto Peabody da Universidade Johns Hopkins (Baltimore). Sob a batuta de Marin, a Osesp fez sua estreia na Philharmonie de Berlim, no Royal Festival Hall de Londres, nos festivais de Lucerna e Edimburgo e na Konzerthaus de Viena, entre outros lugares de primeira importância no cenário mundial. Também viajou pelo Brasil, em 2014, comemorando os 60 anos de criação da Orquestra e lançou em CD (selo Naxos) um ciclo integral das sinfonias de Prokofiev. Ao final de seu mandato de oito anos à frente da Osesp, em dezembro de 2019, Marin receberá o título de Regente de Honra. A decisão é um reconhecimento à parceria que ajudou a elevar o perfil da Orquestra, tanto no cenário nacional quanto internacional, e à sua visão humanista, fonte de inspiração para as atividades educativas e de formação de público da Osesp. A partir de 2020, Marin Alsop será Regente Titular da Orquestra Sinfônica da Rádio de Viena. Disponível em: <http://osesp.art.br/>. Acesso em: 03 abr. 2019.
} 
Para a verificação e contagem do número de mulheres que estiveram presentes na trajetória da orquestra, utilizamos as programações disponíveis no site da orquestra ${ }^{5}$ de todos os anos estudados (2000-2019). Para uma melhor verificação dos dados, suprimimos os concertos de música de câmara, recitais individuais e concertos itinerantes, uma vez que entendemos que os concertos com a orquestra completa teriam maior representatividade para a análise ora demonstrada. Entretanto, consideramos os concertos das turnês internacionais, embora também sejam itinerantes, já que representam a orquestra e o Brasil no cenário da música erudita mundial.

Verificamos todos os nomes de regentes, solistas e compositores, em todos os programas, durante os 20 anos de orquestra. Selecionamos essas posições de trabalho, pois entendemos sua representatividade perante a orquestra e também compreendemos que essas funções são definidas através de "convites" por parte da orquestra. Assim, nos aproximamos do viés assumido pela instituição em convidar e/ou selecionar determinados músicos.

O maestro (ou regente) possui um papel importante em um grupo de câmara, uma vez que representa sua liderança. A construção da performance de uma orquestra se dá a partir do regente, sendo ele quem define as escolhas interpretativas do grupo. Essa é uma razão relevante para que possamos considerar a figura do regente e a quantidade de vezes que maestros ou maestrinas estiveram à frente da orquestra estudada. Para verificar a diferença entre os grupos de maestros e maestrinas atuantes no período entre os anos 2000 e 2011 (período no qual a OSESP ficou sob a regência e direção artística de regentes homens) e 2012 e $2019^{6}$ (período sob a batuta e direção artística de Marin Alsop), realizamos um teste de média, com o intuito de verificar se existe real diferença entre a quantidade de mulheres e homens regentes nos dois períodos. O mesmo teste foi realizado para os grupos de instrumentistas mulheres e homens nas duas condições estudadas.

Anteriormente, discutimos a figura do compositor como um comunicador de ideias e afetos, assumindo, assim, uma posição de destaque e conhecimento (SANTOS, 2018). Entendemos que a invisibilização de composições e nomes femininos do meio educacional e artístico reflete na invisibilidade das mulheres na música erudita, hierarquizando o conhecimento e a não comunicação das diferentes experiências artísticas da figura feminina como parte da construção do pensamento e da arte. Dessa

\footnotetext{
5 Disponível em: <http://osesp.art.br/>. Acesso em: 03 abr. 2019.

6 Coletamos todos os dados apresentados neste trabalho a partir dos programas de concertos disponibilizados no site da orquestra. Sendo assim, pudemos também analisar a programação de 2019, uma vez que ela já se encontra disponível na internet.
} 
maneira, contabilizamos o número de compositores e compositoras para averiguar a possível diferença ou semelhança entre eles, analisando as duas fases da orquestra (2000-2011 e 2012-2019).

Além disso, registramos os nomes das compositoras performadas durante os anos para uma verificação da frequência com que aparecem ao longo do período analisado. Por fim, verificamos os solistas que, embora possuam um papel de menor importância política ${ }^{7}$, atuam em orquestras e outros grupos de câmara através de convites, o que nos mostra a escolha da direção artística em selecionar um ou outro instrumentista. Além disso, entendemos que estar à frente de uma orquestra como solista proporciona uma visão diferente do sujeito, visto que um novo lugar de referência e destaque é ocupado. Entretanto, por entendermos a diferença entre solistas cantores e instrumentistas, contabilizamos as duas categorias de solistas para futura análise.

Obras com solistas cantores acabam englobando os dois gêneros para a composição das vozes específicas, sendo assim, quando for necessária uma voz tenor ou baixo, será solicitado um músico. O mesmo ocorre com as posições de vozes femininas. Por isso, decidimos investigar separadamente os instrumentistas, já que atuar como um pianista ou violinista, por exemplo, não requer especificação de gênero. Acreditamos que a análise da quantidade de solistas masculinos e femininos nos levará a importantes discussões.

\section{Resultados}

Contabilizamos o número de apresentações, além dos nomes e números de regentes, compositores e solistas, em cada ano, entre o período de 2000 a 2019. A Orquestra Sinfônica do Estado de São Paulo conta, em média, com 107 (desvio padrão = 20.66) apresentações por ano. O número de regentes e compositores selecionados durante esse período está ilustrado nas figuras 1 e 2. Já as figuras 5 e 6 mostram as compositoras e regentes que se apresentaram com a orquestra no mesmo período.

Apresentar os nomes nos mostra a frequência com que cada artista está sendo convidada, além de alguns que são titulares da orquestra como, por exemplo, Marin Alsop, quando assumiu a orquestra em 2012 até o presente momento, ou Naomi Munakata, que atua como regente do coro da OSESP desde 2000.

\footnotetext{
7 Discutimos anteriormente que a posição de performer musical, na história da música ocidental de concertos, encontra-se em segundo plano. Embora tenhamos conhecimento de que o corpo como meio de expressão tem a capacidade de confirmar uma ideia ou conhecimento, a história aponta para o intérprete como o ideal de fidelidade e reverência à autoridade do compositor, ainda que também já saibamos que essa máxima de fidelidade é impossível de se concretizar.
} 


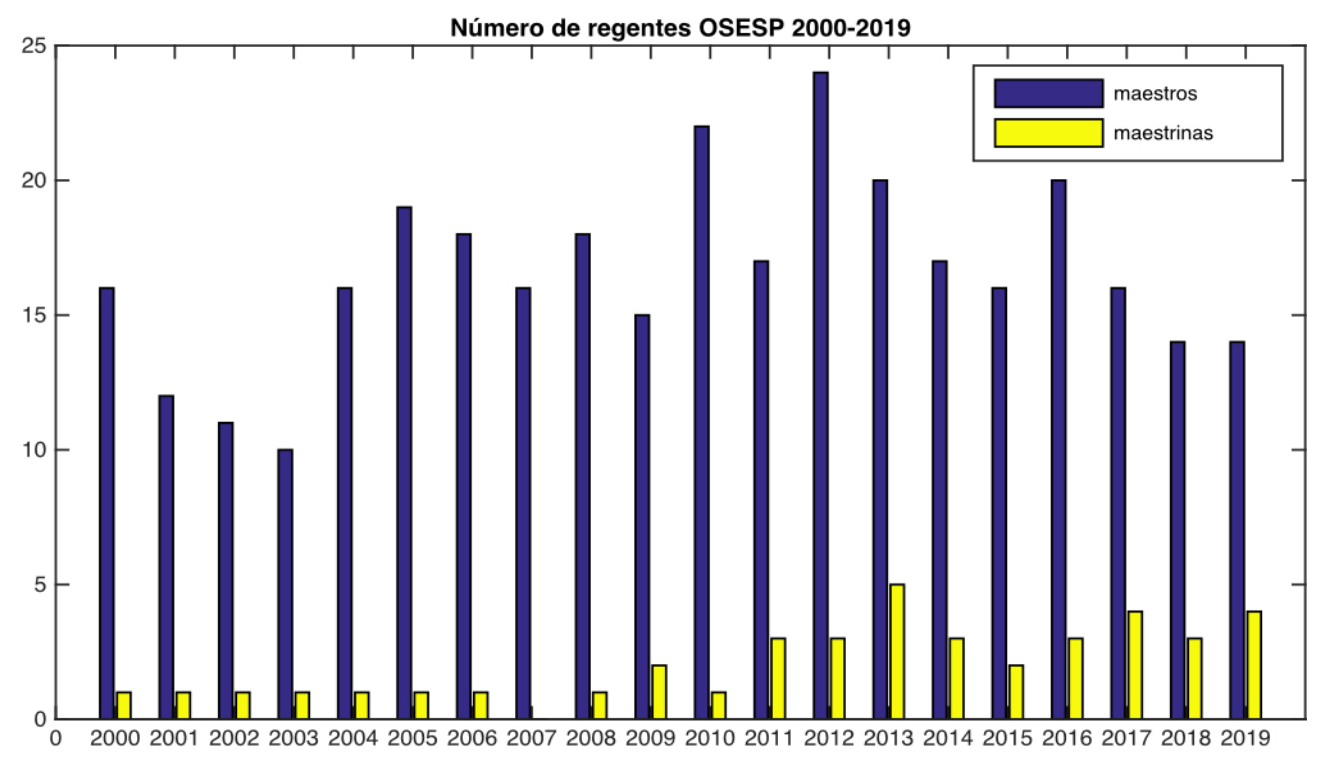

Figura 1: Números de regentes que atuaram na OSESP entre 2000 e 2019, por gênero, sendo as barras azuis a representação dos homens e as amarelas o número de mulheres. Fonte: Elaboração própria (2019).

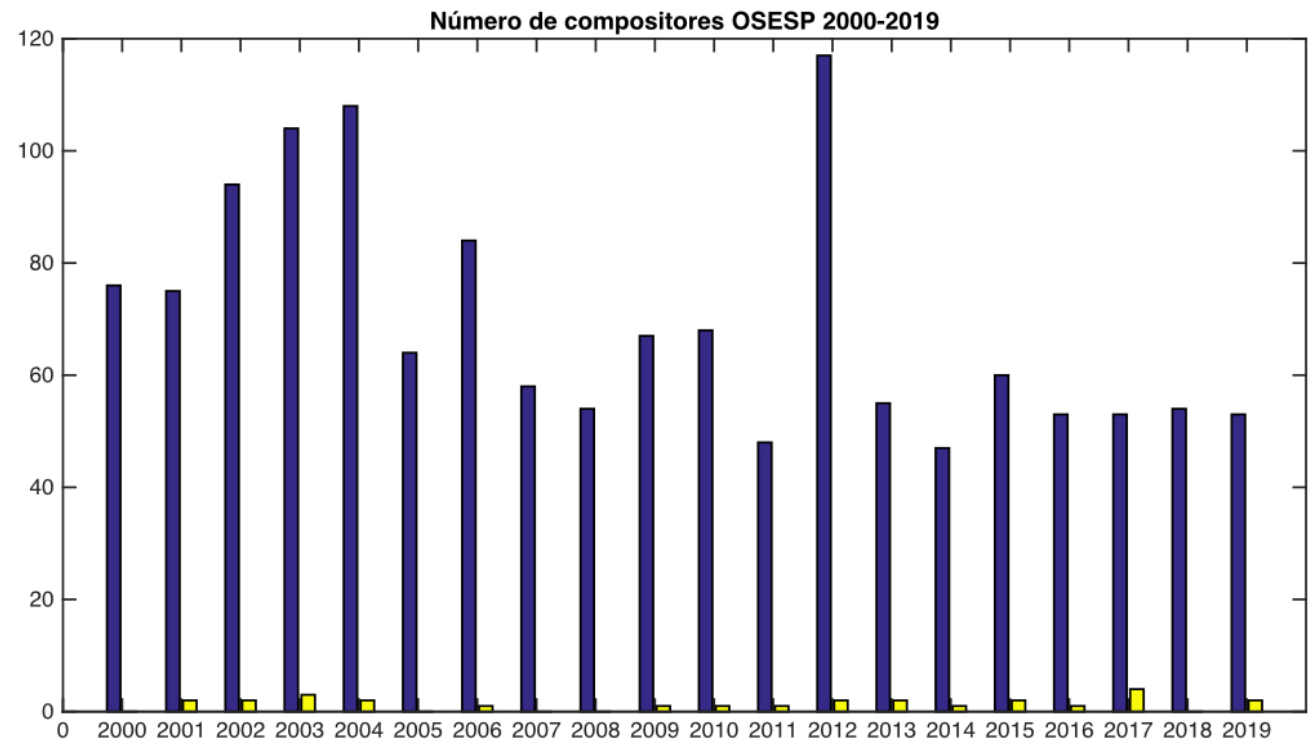

Figura 2: Número de compositores performados pela OSESP entre 2000 e 2019, por gênero, sendo as barras azuis a representação dos homens e as amarelas o número de mulheres. Fonte: Elaboração própria (2019). 


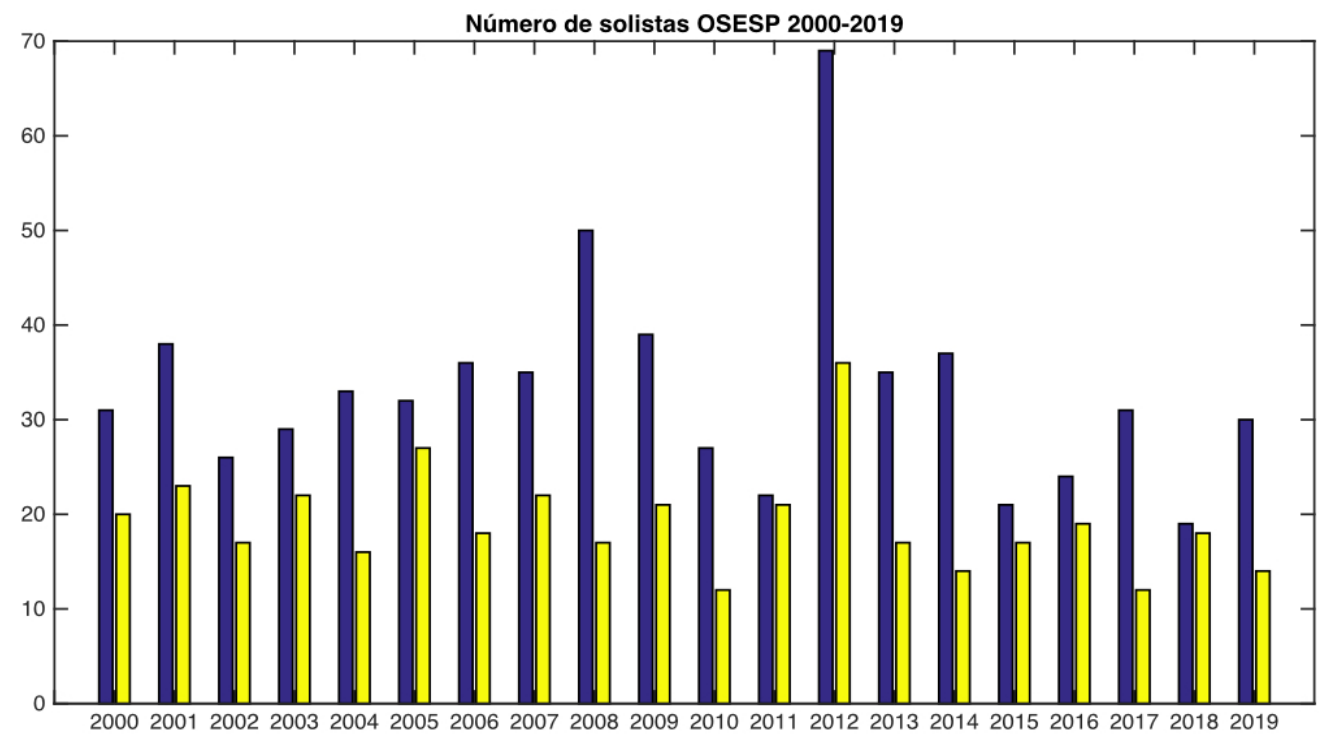

Figura 3: Número de solistas (cantores e instrumentistas) convidados pela OSESP entre 2000 e 2019, por gênero, sendo as barras azuis a representação dos homens e as amarelas o número de mulheres. Fonte: Elaboração própria (2019).

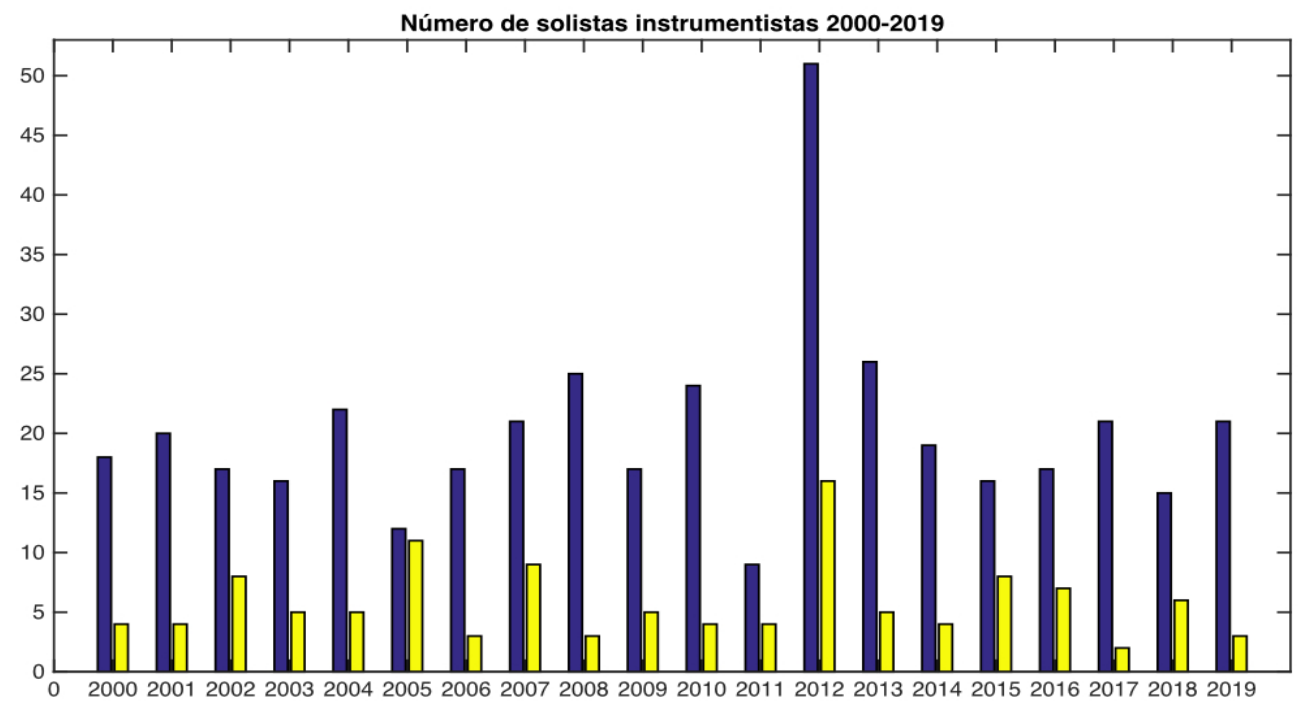

Figura 4: Número de instrumentistas solistas convidados pela OSESP entre 2000 e 2019, por gênero, sendo as barras azuis a representação dos homens e as amarelas o número de mulheres. Fonte: Elaboração própria (2019).

Para uma verificação dos dados dos grupos de maestros e maestrinas e instrumentistas homens e mulheres, antes e durante o período em que Marin Alsop atuou como regente e diretora artística da OSESP, realizamos um teste de médias e apontamos a significativa diferença quando comparado o grupo de regentes e instrumentistas homens e mulheres nos dois períodos estudados. Além disso, apontamos para a significativa similaridade quando comparados os grupos de maestrinas e maestros 
e o grupo de instrumentistas homens e mulheres, separadamente, nas duas condições analisadas.

Todos os testes foram realizados com intervalo de confiança de 95\% (Figura 7). Os resultados apontam para uma relevante diferença quando comparamos homens e mulheres nos dois períodos analisados. Entretanto, quando comparamos maestros com maestros e maestrinas com maestrinas, nas duas condições estudadas, não ocorre nenhuma diferença, demonstrando nenhuma distinção (aumento ou diminuição) entre o número de homens e/ou mulheres antes e durante a gestão de Marin Alsop.

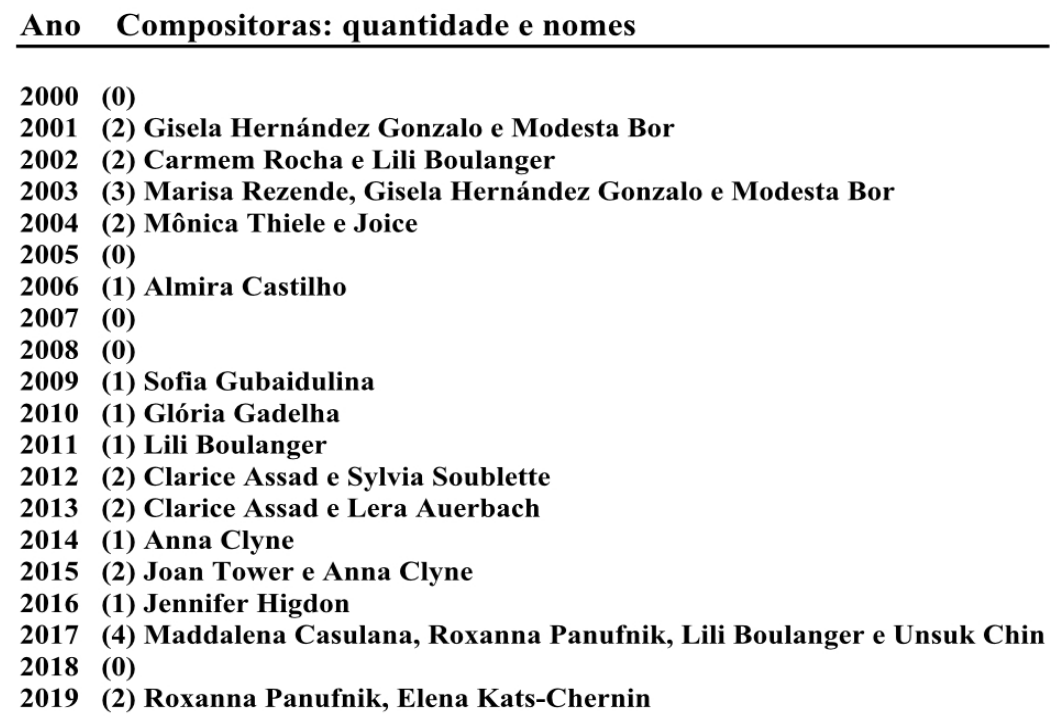

Figura 5: Nome das compositoras a terem suas obras performadas pela OSESP, por ano. Fonte: Elaboração própria (2019).

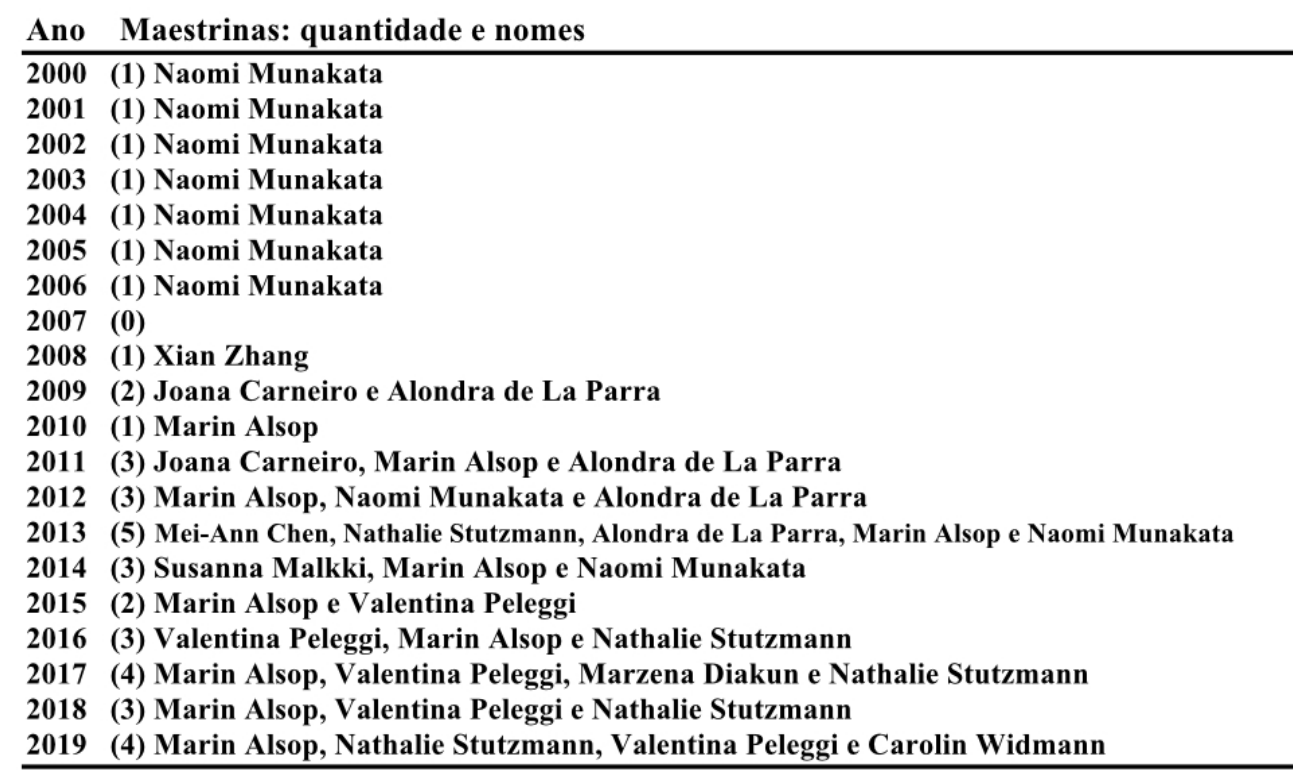

Figura 6: Nome das maestrinas que regeram a OSESP, por ano. Fonte: Elaboração própria (2019). 


\begin{tabular}{l|l|l}
\multicolumn{1}{c}{ Grupos analisados } & \multicolumn{1}{c}{ Condições analisadas } & \multicolumn{1}{c}{ Teste de média } \\
\hline homens/mulheres instrumentistas & Sem Marin Alsop & (I) diferença significativa \\
homens/mulheres instrumentistas & Com Marin Alsop & (I) diferença significativa \\
homens/mulheres regentes & Sem Marin Alsop & (I) diferença significativa \\
homens/mulheres regentes & Com Marin Alsop & (I) diferença significativa \\
mulheres regentes & Com e sem Marin Alsop & (0) nenhuma diferença significativa \\
mulheres instrumentistas & Com e sem Marin Alsop & (0) nenhuma diferença significativa \\
homens regentes & Com e sem Marin Alsop & (0) nenhuma diferença significativa \\
homens instrumentistas & Com e sem Marin Alsop & (0) nenhuma diferença significativa \\
\hline
\end{tabular}

Figura 7 (quadro): Comparação das médias dos diferentes grupos entre as condições, antes e durante a gestão de Marin Alsop como regente e diretora artística da OSESP. Fonte: Elaboração própria (2019).

Como mencionado na seção da metodologia, contabilizamos o número de solistas cantores e instrumentistas e apresentamos, nas figuras 3 e 4, a quantidade de cantores e instrumentistas por gênero, respectivamente.

\section{Discussão}

Com o objetivo de discutir a complexa relação de gênero e política, investigamos as dinâmicas sociais relacionadas à questão e à presença feminina em posições de destaque a partir de formas de poder e dominação. Analisamos a instituição OSESP em duas fases, antes e durante o período de atuação de Marin Alsop. Para isso, nos debruçamos na contabilização de homens e mulheres que atuaram como compositores, regentes e solistas no grupo sinfônico durante 20 anos.

Os resultados apontam para uma significativa diferença entre a quantidade de homens e mulheres que atuaram nas diferentes posições estudadas, sendo convidados ou tendo suas obras performadas pela OSESP. Isso implica em uma menor representatividade feminina e, consequentemente, na confirmação de um protagonismo masculino.

Em trabalho anterior, similarmente a este estudo, investigamos o número de compositores que tiveram sua obras performadas por orquestras brasileiras no último ano (2018) e discutimos acerca da diferença quantitativa entre homens e mulheres na figura do compositor (SANTOS, 2018). Esse estudo teve como base o entendimento de que o compositor assume o lugar de fala e que o ato de falar não é neutro. Muito pelo contrário. Quem fala comunica seus vieses interpretativos e suas características culturais e sociais. Sendo assim, entendemos que essa oportunidade de falar gera uma hierarquização, atribuindo poder e exclusividade ao pensamento e à divulgação de apenas um conhecimento dominante. 
A presente investigação corrobora com os resultados anteriores, apontando para a larga diferença no número de obras compostas por homens e mulheres executadas pela OSESP ao longo dos 20 anos de instituição. Ribeiro (2017) traz para a discussão a pensadora e feminista negra Lélia Gonzalez, que discute a ideia de hierarquização dos saberes e como o privilégio epistêmico do saber dominante, consequentemente, gera a inviabilização de outras experiências artísticas da figura feminina, como parte da construção do pensamento e da arte.

Entendemos que a não inclusão de nomes de compositoras faz com que essas mulheres tenham seu lugar de fala restringido, gerando, assim, uma invisibilidade da figura de compositoras na área da música erudita. Ribeiro (2017) ainda aponta para uma palestra de Grada Kiolomba, em 2016, na qual a oradora discute a descolonização do conhecimento, refletindo sobre a necessidade de ruptura das hierarquias consolidadas. O termo epistemologia é definido por Kiolomba como "a ciência da aquisição de conhecimento" (RIBEIRO, 2017, p. 88). Sendo assim, ela não definiria apenas como se produz o conhecimento, mas quem o produz, ressaltando quem tem o poder de falar.

Na figura 5 podemos observar os nomes das compositoras que tiveram suas obras performadas pela OSESP durante os 20 anos estudados e notamos a quase inexistente repetição de suas obras ao longo dos programas e dos anos. Ao contrário, obras de compositores como Mahler, Beethoven, Mozart, Bernstein, Guarnieri, Villa-Lobos etc., aparecem em todos os anos, mais de uma vez, nas programações anuais. Compreendemos, assim, que existe uma hierarquização de conhecimento e poder definido e expressado pela instituição. Rosa e Nogueira (2015) refletem sobre as compositoras apresentadas em disciplinas do curso de música no Brasil e apontam para sua invisibilização por parte dos docentes, observando, assim, o silenciamento da figura feminina no meio acadêmico. Ao questionarem os alunos sobre quantas compositoras tiveram conhecimento durante seus cursos de graduação, percebe-se a ausência de nomes femininos, o que corrobora para uma lacuna na formação dos futuros educadores musicais. Dessa maneira, ocorre a exclusão do conhecimento pela figura feminina, uma vez que o ato de compor comunica ideias e afetos, além de envolver aspectos de integração social e significações, considerando também a relação de poder discutida anteriormente.

Ao observarmos a enorme diferença no número de compositores e compositoras durante os 20 anos de trajetória da orquestra, torna-se clara a invisibilidade da figura de compositoras comunicada pela OSESP, ficando evidente a necessidade de um profundo debate sobre tal temática. Ribeiro (2017) aponta para a urgência de uma ruptura 
do pensamento hegemônico e a ressignificação das identidades, sejam de raça, gênero, classe para que se pudesse construir novos lugares de fala com o objetivo de possibilitar voz e visibilidade a sujeitos que foram considerados implícitos dentro dessa normatização hegemônica (RIBEIRO, 2017, p. 43).

Os resultados dos testes de média envolvendo os grupos de regentes e solistas mostram uma diferença significativa quando comparamos os grupos de homens com o de mulheres nas duas condições estudadas. Os resultados significam que o número de regentes e instrumentistas homens apresenta-se sempre maior que o número de regentes e instrumentistas mulheres, nunca ocorrendo diferença entre os dois grupos quando comparamos as médias entre os grupos de homens/mulheres.

Com 95\% de confiança, os resultados mostram, ainda, que nenhuma diferença ocorre quando comparamos os grupos de maestrinas/maestrinas e musicistas/musicistas e o grupo de maestros/maestros e músicos instrumentistas/músicos instrumentistas nas duas condições. Em outras palavras, não houve diferença significativa (aumento ou diminuição) no número de homens e mulheres regentes e instrumentistas nos períodos que antecederam e durante a gestão de Marin Alsop.

Como dito anteriormente, a escolha por contabilizar o número de regentes e solistas vem do entendimento de que essas posições são ocupadas por meio de convites realizados pela direção artística da orquestra. A representatividade da figura do regente corrobora para o estudo político e de representação de identidade. Por fim, os solistas que, embora exerçam um papel menos importante politicamente, proporcionam uma visão diferenciada do sujeito, ocupando, assim, um novo lugar de referência e destaque.

Por entendermos a distinção entre solistas cantores e instrumentistas, contabilizamos as duas categorias de musicistas, uma vez que as obras com conjunto de vozes englobam os dois gêneros para a composição das vozes específicas solicitados pelos compositores das obras. Dessa maneira, calculamos separadamente os instrumentistas, acreditando que a quantidade de músicos e musicistas apontam, novamente, para a complexa e acentuada relação de gênero na música erudita no Brasil.

Embora o número de mulheres instrumentistas seja superior ao número de mulheres como compositoras ou regentes, ainda se encontra muito distante da igualdade entre os gêneros. Segundo Miguel (2014a), em uma sociedade estruturada de acordo com a dominação masculina, a figura da mulher não é apenas diferente, mas exerce uma posição social marcada pela subalternidade. O pesquisador explica que as mulheres têm menos acesso às posições de poder e de controle e, consequentemente, de bens materiais e, por isso, são mais propícias à humilhação e violência, fazendo com que a figura 
feminina seja considerada frágil, inferior e pouco racional. Ainda é necessário romper com essa estrutura, contribuindo para a emancipação das mulheres e a revisão da posição social privilegiada ocupada pelos homens.

A fala das mulheres carrega marcas de inferioridade, desde a disposição afetiva associada a elas, julgada como excessivamente compassiva, até o próprio timbre de voz, já que o mais grave é vinculado socialmente ao exercício da autoridade. Por fim, os interesses do grupo dominante são mais facilmente apresentados como interesses universais, o que é outro efeito do "imperialismo cultural" - a cultura e a vivência do grupo dominante são universalizadas e vistas como a norma (MIGUEL, 2014b, p. 106).

Nossos resultados também apontam para a discussão proposta pela pesquisadora Flávia Biroli (2018), ao mostrar que a divisão de trabalho, no ambiente público e privado, comunica dinâmicas sociais de desvantagens, sejam elas materiais e/ou simbólicas, que se entrelaçam aos espaços formais de representação, historicamente considerados masculinos. Sendo assim, a pouca presença das mulheres em cargos de primeiro escalão não significa que elas não atuem na posição descrita (veja a figura de Marin Alsop), mas, sim, que tal atuação é dificultada e, quando efetivamente existe, ocorre em espaços públicos "masculinos", como a instituição orquestra sinfônica, por exemplo.

A partir dessa discussão, é importante notar dois argumentos relevantes sobre o feminismo e a política. O primeiro deles é que o fato de terem o mesmo gênero não significa que as mulheres, apenas por serem mulheres, responderão a interesses idênticos. O pesquisador Luis Felipe Miguel (2014a) explica que o mesmo indivíduo ocupa, simultaneamente, diferentes "posições de sujeito", as quais englobam variadas imposições que, em muitos casos, são contraditórias. $\mathrm{O}$ autor ainda aponta que muitas mulheres na política não são comprometidas com as questões de gênero e que outras discordam sobre quais interesses e medidas políticas devem apoiar.

Por outro lado, o mesmo autor acrescenta à discussão o ponto de vista de Anne Philips (1993), trazendo para o debate a diferenciação entre interesses e identidade: ${ }^{8}$

O meu interesse é, em tese, representável por qualquer pessoa, que pode verbalizá-lo em meu lugar e agir para promovê-lo. Mas a minha identidade só se torna visível por meio de um igual. Eu posso não estar presente no grupo de governantes, mas minha identidade estará lá não por meio de um representante, e sim corporificada em alguém que a possui em comum. (MIGUEL, 2014, p. 100)

\footnotetext{
8 Em publicações posteriores, a própria Anne Philips substitui o termo "identidade" por "perspectivas sociais". Luis Felipe Miguel (2014, p. 100) explica que o termo se apresenta "menos fechado e com caráter mais relacional" e a ideia de perspectiva social assume uma função similar à de identidade, considerando o que não é representável, cumprindo a exigência na presença política.
} 
Assim, entendemos que o fato de Marin Alsop assumir o posto de regente e diretora artística não faz com que assuma decisões envolvendo questões de gênero, além de desconstruir o argumento de que as mulheres, necessariamente, "precisam ocupar espaços de poder para defender seus interesses específicos, o que pressupõe a existência de interesses comuns de antemão" (MIGUEL, 2014a, p. 101). Compreendemos também a falsa premissa de que as mulheres possuem características de sensibilidade diferentes dos homens, fazendo com que elas sejam pré-dispostas a "uma política mais altruísta e humana" (MIGUEL, 2014a, p. 101).

Entretanto, a figura feminina, quando ocupa posições de regência e solista, propicia uma visão de identidade para outras mulheres. Mesmo sabendo que, na maioria das vezes, elas não se encontram presentes nos mais altos escalões de decisões políticas e mesmo não se sentindo representadas pelas decisões das poucas que têm acesso a tais posições, a identidade feminina encontra-se presente, gerando um viés comum com outras tantas.

O fato do não reconhecimento da figura feminina em posições de destaque gera nas outras uma descrença em suas próprias capacidades intelectuais, uma vez que não identificam a ascensão profissional como uma possibilidade para si. Dessa maneira, a corporificação do sujeito feminino, em posições de poder e destaque, proporciona um processo de empoderamento na nova geração de mulheres instrumentistas, regentes e compositoras.

O segundo argumento sobre feminismo e política é que o acesso a posições formais na estrutura de poder não necessariamente faz com que esse sujeito assuma posições de igualdade em relação a outros presentes na mesma estrutura. Miguel (2014) explica que a política é um espaço social hierarquizado e faz com que aqueles que nela ingressam sejam submetidos à sua estrutura, devendo aceitar determinadas lógicas e certos padrões de comportamento sob pena de serem marginalizados.

Com essa análise, torna-se inviável, a partir dos nossos dados, medir a quantidade de poder de decisão da maestrina na posição em que atua na orquestra. É importante mencionar novamente que nosso estudo não tem como objetivo avaliar o poder político de Marin Alsop, mas contabilizar o número de homens e mulheres atuantes em posições de destaque na OSESP, apontando para a representatividade e a necessidade de discussão sobre a (in)visibilidade do feminino no meio musical erudito no Brasil.

Nossos dados apresentam apenas a quantidade de mulheres convidadas e/ou selecionadas para compor a programação da orquestra durante 20 anos de atuação, a qual dividimos em duas fases, anterior e posterior a Marin Alsop assumir o cargo, contabilizando as diferenças e semelhanças nos grupos estudados. É importante lembrar 
que as formas mais complexas de dominação, assim como a estrutura social patriarcal, exigem métodos e estratégias mais sofisticadas para a sua compreensão.

Por isso, tornam-se necessários outros trabalhos envolvendo a temática para que possamos cada vez mais nos aproximar do assunto. Marin Alsop assumiu a OSESP em 2012 e completa sua trajetória este ano (2019), sendo cedo para medir e discutir o possível impacto que sua figura e representatividade têm na estrutura da instituição e nas futuras gerações.

\section{Conclusão}

Nossos resultados mostram que as mulheres buscam ocupar posições de destaque e poder. Entretanto, há uma significativa diferença em relação ao número de homens que exercem a mesma função. Assim, compreendemos que falar de mulheres no meio musical erudito não é apontar para uma ausência - muito pelo contrário, existem mulheres ocupando a posição de regente, compositoras e solistas em orquestras brasileiras. Contudo, sua presença ainda é significativamente reduzida, uma vez que o espaço masculino corrobora para essa invisibilização.

Neste estudo buscamos entender um importante ponto para a análise da temática - a identidade feminina em posição de destaque -, discutindo, assim, como a figura da mulher em uma posição política de poder pode impactar no meio musical no qual a instituição está inserida. Para isso, buscamos considerar o sujeito feminino no meio musical, percebendo sua identidade e sua perspectiva social como uma representante de um grupo político. Nossos resultados buscam traçar e explorar as relações de poder político e o feminismo, discutindo sobre a hierarquia dos saberes e a inserção das mulheres em posições de destaque de instituições da música erudita no Brasil.

Reconhecemos que este é um estudo exploratório, apontando para a necessidade de aprofundamento da temática, em diferentes campos do conhecimento, como, por exemplo, na estrutura das políticas públicas, na educação e pesquisa, buscando, principalmente, a expansão para um estudo interseccional. O que queremos é uma política mais igualitária, implicando no enfrentamento das questões de gênero, assim como de classe e de raça.

Por fim, apontamos que discutir a questão do lugar de fala em um campo masculinizado e regido por valores patriarcais torna-se pertinente, uma vez que falar sobre a figura feminina de poder e liderança não significa, necessariamente, uma política de inclusão das mulheres, o que fica comprovado a partir deste estudo. Entretanto, acreditamos que fomentar a pesquisa em música e gênero, como já tem sido feito, torna- 
se uma estratégia de mudança e resistência da área, além da produção de conhecimento sobre o assunto.

\section{Referências}

AMÂNCIO, L. As assimetrias nas representações do gênero. Revista Crítica de Ciências Sociais, v. 34, pp. 9-22, 1992.

BERTH, J. O que é empoderamento? Belo Horizonte: [s.n.], 2018.

BIROLI, F. Gênero e desigualdades: os limites da democracia no Brasil. São Paulo: Boitempo, 2018.

CARNEIRO, S. Identidade feminina. In: HELEIETH, S.; MUÑOZ VARGAS, M. (Org.). Mulher brasileira é assim. Rio de Janeiro: Rosa dos Tempos, 1994. pp. 187-194.

COSTA, L. C. DA S. "A gente chega e invade as quebradas": Identidade Social de mulheres MC. 2016. 286 f. Dissertação (Faculdade de Psicologia). - Universidade Federal de Minas Gerais, 2016.

DOMENICI, C. A performance musical e o gênero feminino. In: NOGUEIRA, I. P.; FONSECA, S. C. (Org.). Estudos de gênero, corpo e música: abordagens metodológicas. Goiânia / Porto Alegre: ANPPOM, 2013. pp. 89-109.

FREIRE, V.; PORTELA, A. C. H. Mulheres compositoras - da invisibilidade à projeção internacional. In: NOGUEIRA, I.; FONSECA, S. C. (Org.). Estudos de gênero, corpo e música: abordagens metodológicas. Goiânia / Porto Alegre: [s.n.], 2013. pp. 279-302.

MIGUEL, L. F. Gênero e representação política. Feminismo e política: uma introdução. São Paulo: Boitempo, 2014a. .

O feminismo e a política. Feminismo e política: uma introdução. São Paulo: Boitempo, 2014b. pp. 17-29.

MIGUEL, L. F. O feminismo e a política. Feminismo e política: uma introdução. São Paulo: Boitempo, 2014c. pp. 17-30.

MIGUEL, L. F.; BIROLI, F. Feminismo e política: uma introdução. São Paulo: Boitempo, 2014.

PETRILLI SEGNINI, L. R. Os músicos e seu trabalho: Diferenças de gênero e raça. Tempo Social, v. 26, n. 1, pp. 75-86, 2014.

- Trabalho, imigração e relações de gênero no contexto da mundialização: músicos do Leste europeu no Brasil. Revista Latinoamericana de Estudios del Trabajo, v. 22, n. 37, pp. 221-250, 2018.

PHILlIPS, A. Democracy and difference. [S.l.]: The Pennsylvania State University Press, 1993.

RIBEIRO, D. O que é: lugar de fala? Belo Horizonte: Editora Letramento, 2017.

ROSA, L. et al. Epistemologias feministas e produção de conhecimento recente sobre mulheres e música no Brasil: algumas reflexões. In: NOGUEIRA, I.; FONSECA, S. (Org.). Estudos de gênero, corpo e música: abordagens metodológicas. Goiânia / Porto Alegre: [s.n.], 2013. pp. 110-136.

ROSA, L.; NOGUEIRA, I. O que nos move, o que nos dobra, o que nos instiga: notas sobre epistemologia feministas, processos criativos, educação e possibilidades transgressoras em música. Revista Vórtex, v. 3, n. 2, p. 25-56, 2015. 
SANTOS, T. F. A (In)visibilidade do feminino na música erudita brasileira. Vitória: [s.n.], 2018. p. 953-966.

ZERBINATTI, C. D.; NOGUEIRA, I. P.; PEDRO, J. M. A emergência do campo de música e gênero no Brasil: reflexões iniciais. Descentrada, v. 2, n. 1, pp. 1-18, 2018. 